\title{
Suspension Training: A New Approach to Improve Muscle Strength, Mass, and Functional Performances in Older Adults?
}

\author{
Vitor Angleri, Samuel Domingos Soligon, Deivid Gomes da Silva, \\ João Guilherme Almeida Bergamasco and Cleiton Augusto Libardi ${ }^{\star}$ \\ MUSCULAB - Laboratory of Neuromuscular Adaptations to Resistance Training, Department of Physical Education, Federal \\ University of São Carlos, São Carlos, Brazil
}

Keywords: suspension training, muscle strength, muscle mass, functional performance improvement, older adults

\section{INTRODUCTION}

OPEN ACCESS

Edited by:

François Billaut,

Laval University, Canada

Reviewed by:

Olaf Prieske,

University of Applied Sciences for

Sports and Management

Potsdam, Germany

Nicolas Berryman,

Bishop's University, Canada

*Correspondence:

Cleiton Augusto Libardi

c.libardi@ufscar.br

Specialty section

This article was submitted to

Exercise Physiology,

a section of the journal

Frontiers in Physiology

Received: 19 August 2019 Accepted: 16 December 2019 Published: 10 January 2020

Citation:

Angleri V, Soligon SD, da Silva DG,

Bergamasco JGA and Libardi CA (2020) Suspension Training: A New

Approach to Improve Muscle

Strength, Mass, and Functional

Performances in Older Adults?

Front. Physiol. 10:1576.

doi: 10.3389/fphys.2019.01576
After the fifth decade of life, the natural aging process leads to annual reductions of $1.5 \%$ and 1$2 \%$ in muscle strength and mass, respectively (Morley et al., 2014; Zembron-Łacny et al., 2014). Additionally, muscle power is also reduced by $3-4 \%$ annually in older subjects (Macaluso and De Vito, 2004). These changes in the neuromuscular system are associated with impairments in functional performance (e.g., motor performance, control, balance, and mobility), increasing morbidity and mortality risks (Frontera et al., 2008; Cruz-Jentoft et al., 2010; Morley et al., 2014; Marty et al., 2017; McGlory et al., 2019).

Different resistance training (RT) modes have been proposed as effective interventions for enhancing muscle strength, mass, power, and functional performance in older adults [ChodzkoZajko et al., 2009; American College of Sports Medicine position stand (ACSM), 2011]. However, less investigated RT modes also appear capable of optimizing these essential adaptations for older adults. Suspension training (ST) is a RT mode in which body segments are attached to suspended hanging straps, creating an unstable environment and using the body weight against gravity to perform multi-planar and multi-joint exercises (Byrne et al., 2014; Mok et al., 2015; Cugliari and Boccia, 2017). Interestingly, ST provides a progressive stimulus in the target muscles and a substantial activation in core muscles, suggesting it could be a promising RT mode to optimize muscle strength, mass, power, and functional performance (Maté-Muñoz et al., 2014; Ma et al., 2017).

The purpose of this manuscript is to provide rationale as to why ST could be a viable RT mode for increasing muscle strength, mass, power, and functional performance in older adults.

\section{EFFECTS OF TRADITIONAL RESISTANCE TRAINING ON MUSCLE STRENGTH, MASS, POWER, AND FUNCTIONAL PERFORMANCE IN OLDER ADULTS}

Current guidelines widely recommend RT programs to mitigate age-related impairments in muscle strength, mass, power, and functional performance in older adults [Nelson et al., 2007; ChodzkoZajko et al., 2009; American College of Sports Medicine position stand (ACSM), 2011]. In order to optimize muscle strength and mass gains in older adults, RT should be performed at least twice weekly, with 8-10 exercises for major muscle groups at moderate to high intensities and slow 
velocity (i.e., progressive RT [PRT]) (Nelson et al., 2007; Chodzko-Zajko et al., 2009; Fragala et al., 2019). In addition, if low loads are used, repetitions should be performed up to concentric failure in order to optimize adaptations (Van Roie et al., 2013). The PRT mode can also improve power and functional performance (Chodzko-Zajko et al., 2009; Churchward-Venne et al., 2015; Van Abbema et al., 2015; Fragala et al., 2019). However, these results are inconsistent (Skelton et al., 1995; de Vreede et al., 2005; Orr et al., 2008; Liu and Latham, 2009, 2011). For instance, two studies of Walker and colleagues showed that PRT [3 sets of 8-14 repetitions at 60$85 \%$ 1-RM (Walker et al., 2015) or 2-3 sets of 14-20 reps at 50-60\% 1-RM] (Walker et al., 2017) was effective in increasing muscle strength and mass but did not increase muscle power or functional performance (i.e., $7.5 \mathrm{~m}$ forward walk, $7.5 \mathrm{~m}$ backward walk, timed up-and-go test, and loaded 10-stair climb test) in older adults. Additionally, de Vreede et al. (2005) randomized 98 older women in a 12 -week exercise program of functionaltask exercise training $(n=33 ; 40$ min of core exercises based on daily tasks) or PRT ( $n=34 ; 3$ sets of 10 repetitions with load progression). The remaining women were assigned to a control group ( $n=31$; kept their daily habits). Results showed improvements in functional performance only for the functionaltask exercise group and muscle strength gains only for PRT. Furthermore, a meta-analysis with 121 trials (6,700 participants [ $>60$ years]) showed that PRT resulted in a large and positive effect on muscle strength, while RT-induced effects on functional performance parameters ranged from small to large (Liu and Latham, 2009). For instance, the effects were moderate to large for chair rise, modest for gait speed (i.e., speed employed during the gait) and small and/or non-significant for balance and timed walk (i.e., time necessary to walk a set distance; Liu and Latham, 2009). Collectively, although PRT appears to be effective for enhancing muscle strength and mass, these gains may not be effectively transferred to power and functional performance (Orr et al., 2008; Granacher et al., 2013a; Fragala et al., 2019).

Regarding muscle power and functional performance improvements, recent guidelines recommend performing PRT in association with other RT modes specifically designed to this purpose within the same RT program (Chodzko-Zajko et al., 2009; Fragala et al., 2019). One RT mode deemed appropriate for this is power training (PT; i.e., using low to moderate intensities and maximal velocity; Chodzko-Zajko et al., 2009; Fragala et al., 2019). Fielding et al. (2002) compared the effects of PRT (3 sets of 8 reps at $70 \% 1-\mathrm{RM}$ performed with $2 \mathrm{~s}$ for both concentric and eccentric actions) and PT (3 sets of 8 reps at 70\% 1-RM performed at maximal velocity) on muscle power in older women. Results showed greater increases in muscle power for PT compared with PRT. Also, Ramírez-Campillo et al. (2014) showed higher increases in functional performance for PT (3 sets of 8 reps at $45-75 \% 1-\mathrm{RM}$ performed at maximal velocity) compared with PRT (3 sets of 8 reps at 75\% 1-RM performed with $3 \mathrm{~s}$ for each muscle action) in older women. Finally, Bottaro et al. (2007) demonstrated that PT (3 sets of $8-10$ reps at $60 \%$ 1 -RM performed at maximal velocity) produced higher increases in muscle power and functional performance compared with PRT (3 sets of 6-8 reps at 60\% 1-RM performed with 2-3s for each contraction) in older men. Considering that age-related impairments are greater in muscle power than muscle strength and mass, it is likely that PT could be a more specific RT mode compared to PRT for functional performance (Macaluso and De Vito, 2004; Petrella et al., 2004; Orr et al., 2008; Fragala et al., 2019).

Improving muscle power is not the only way to enhance functional performance. It has been suggested that the activation of the core muscles (i.e., muscle group composed of the abdominals, glutes, paraspinal, diaphragm, hip girdle, and pelvic floor; Gringmuth and Jackson, 2000) can play an important role in functional performance, as this muscle group allows power propagation to the body's extremities (Shinkle et al., 2012; Granacher et al., 2013a; Aguilera-Castells and Busca, 2018). Accordingly, a systematic review demonstrated that RT aimed at enhancing core muscle strength can be an alternative approach for balance/mobility and functional performance promotion in older adults (Granacher et al., 2013a). Additionally, the core muscles are responsible for balance maintenance and functional performance. It also allows daily life activities to be performed even on relatively unstable situations (e.g., during manipulation of unstable loads and/or walking on an irregular pavement; Behm and Anderson, 2006; Kibele and Behm, 2009; Behm et al., 2013; Granacher et al., 2013b; Aguilera-Castells and Busca, 2018). Therefore, considering the principle of training specificity, RT modes should attempt to simulate unstable environments when aiming to improve functional performance (Behm, 1995; Behm and Anderson, 2006; Aguilera-Castells and Busca, 2018).

\section{SUSPENSION TRAINING AS A NEW APPROACH TO OPTIMIZE IMPROVEMENTS IN MUSCLE STRENGTH, MASS, POWER, AND FUNCTIONAL PERFORMANCE IN OLDER ADULTS}

In the past years, strategies aiming to stimulate the core muscles through the simulation of an unstable training environment have been proposed (e.g., Balance Board ${ }^{\circledR}$, BOSU ${ }^{\circledR}$, and Swiss Ball) (Byrne et al., 2014; Cugliari and Boccia, 2017; AguileraCastells and Busca, 2018). In ST instance, instability is simulated by suspending the body's segments thought hanging straps, which creates an unstable environment where multi-planar and multi-joint exercises are performed using body weight and gravity as load agents (Byrne et al., 2014; Mok et al., 2015; Cugliari and Boccia, 2017). The ST is a RT mode that has a simple configuration, takes up little space, can be adjusted to the practitioners' requirements and permits a great variety of exercises (Figure 1). Although no study has investigated ST's safety, this method allows the adjustment and progression of the instability and training overload, even for frail elderly. Importantly, studies investigating the acute effects of ST support the notion that this RT mode may produce substantial improvements on functional performance due to a higher activation of the core muscles compared with RT modes performed on stable environment (e.g., PRT; JiménezGarcía et al., 2019). In fact, Harris et al. (2017) compared the 

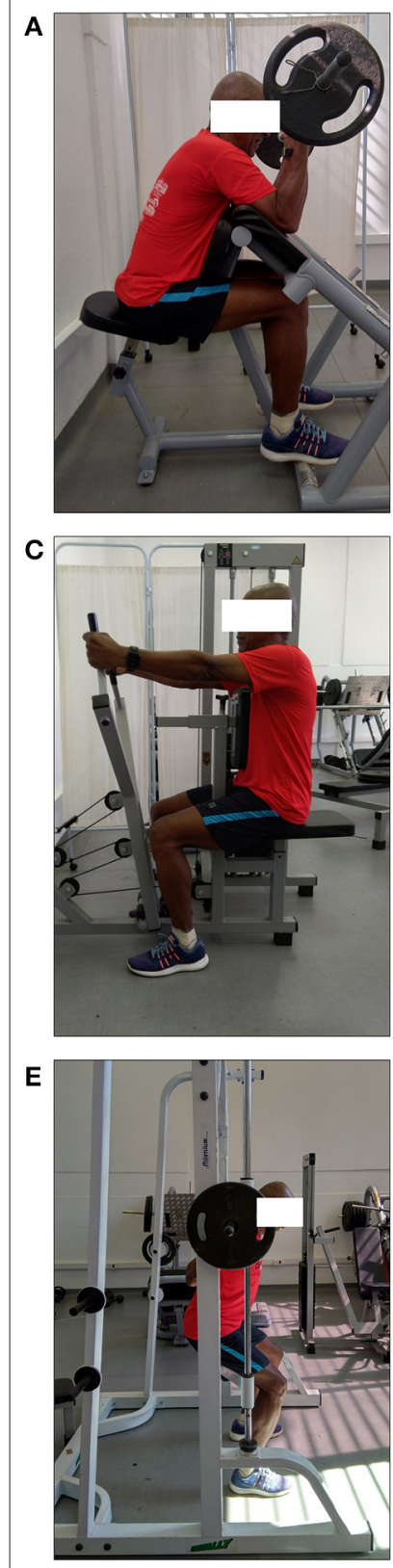

FIGURE 1 | Exercise approaches in different training programs. Resistance training: elbow flexion (A), seated row (C), and squat (E). Suspension training: elbow flexion (B), seated row (D), and squat (F).

effects of push-up, inverted row, bridge and plank exercises performed in the PRT configuration (i.e., stable environment) with the same exercises performed using ST (i.e., unstable setup) on trunk and core muscles activation in healthy adults. Results showed a higher activation of core muscles for ST compared with the stable PRT scheme. Additionally, a recent systematic review including 16 studies showed higher activation of core muscles for ST compared with PRT in the pushup, inverted row, prone bridge, and hamstring curl exercises (Aguilera-Castells and Busca, 2018). Regarding the chronic effects of ST, Ma et al. (2017) showed higher increases in core muscle strength and power for ST compared with PRT. Furthermore, Maté-Muñoz et al. (2014) compared the effects of PT and ST performed with the same exercises and maximal velocities. Results showed that ST is as effective as PT for improving the strength, power and movement velocity. However, these studies were performed with young (Maté-Muñoz et al., 2014) and trained cohorts (Ma et al., 2017). Therefore, future studies should investigate the effects of ST in older adults. Collectively, these studies allow us to suggest that the higher core activation inherent of ST, associated with its effectiveness in increasing muscle power, can make it a promising RT mode when aiming to improve functional performance in older adults.

Regarding muscle strength and mass gains, we (Barcelos et al., 2018; Nobrega et al., 2018; Damas et al., 2019) and other groups (Ahtiainen et al., 2005; Morton et al., 2016; Schoenfeld et al., 2016) have shown that exercising to concentric muscle failure produces similar increases in these neuromuscular adaptations despite different training variables or modes' manipulation. A recent study of Damas et al. (2019) reported similar muscle hypertrophy between a standard PRT and a protocol that systematically manipulated RT variables (i.e., exercise load, number of repetitions, type of muscle contraction, and inter set rest interval), both performed to concentric failure in resistance-trained men. Accordingly, other studies showed similar increases in muscle strength and mass in healthy adults when both bench press and push-ups (performed with body weight, likewise ST) were performed to concentric failure (Calatayud et al., 2015; Kikuchi and Nakazato, 2017). Hence, current literature points toward similar neuromuscular adaptations when exercising to concentric muscle failure, regardless of RT mode or scheme utilized (Burd et al., 2010; Damas et al., 2019). Although this hypothesis should be tested in the older population, evidence suggest that both traditional RT modes (e.g., PRT and PT) and ST would promote similar increases in muscle strength and mass when performed up to concentric muscle failure. If these hypotheses are confirmed, ST would therefore be a viable approach to produce improvements in muscle strength, mass, muscle power, and enhance functional performance.

\section{CONCLUSION}

In summary, different RT modes such as PRT and PT could be used within the same RT program to improve muscle strength, mass, power, and functional performance. Additionally, the literature allows us to hypothesize that ST would be an alternative RT mode capable of increasing muscle strength, mass, power and functional performance due to the high activation of the core muscles induced by the instability, especially if sets are performed up to concentric failure. Finally, future studies should investigate the effects of ST on these outcomes in older adults. To investigate this paradigm, studies should measure muscle strength, mass outcomes, and functional performance through a 
battery of functional tests (e.g., habitual and maximal gait speed, chair stand, timed up-and-go and rate of torque development).

\section{AUTHOR CONTRIBUTIONS}

All authors contributed to the development of the manuscript, reviewed it, and approved the content of the final version.

\section{REFERENCES}

Aguilera-Castells, J., and Buscà, B. (2018). Muscle activation in suspension training: a systematic review. Sports Biomech. 19, 55-75. doi: 10.1080/14763141.2018.1472293

Ahtiainen, J. P., Pakarinen, A., Alen, M., Kraemer, W. J., and Hakkinen, K. (2005). Short vs. long rest period between the sets in hypertrophic resistance training: influence on muscle strength, size, and hormonal adaptations in trained men. J. Strength Cond. Res. 19, 572-582. doi: 10.1519/00124278-200508000-00015

American College of Sports Medicine position stand (ACSM) (2011). Quantity and quality of exercise for developing and maintaining cardiorespiratory, musculoskeletal, and neuromotor fitness in apparently healthy adults: guidance for prescribing exercise. Med. Sci. Sports Exerc. 43, 1334-1359. doi: 10.1249/MSS.0b013e318213fefb

Barcelos, C., Damas, F., Nobrega, S. R., Ugrinowitsch, C., Lixandrao, M. E., Marcelino Eder Dos Santos, L., et al. (2018). High-frequency resistance training does not promote greater muscular adaptations compared to low frequencies in young untrained men. Eur. J. Sport Sci. 18, 1077-1082. doi: 10.1080/17461391.2018.1476590

Behm, D. G. (1995). Neuromuscular implications and applications of resistance training. J. Strength Cond. Res. 9, 264-274. doi: 10.1519/00124278-199511000-00014

Behm, D. G., and Anderson, K. G. (2006). The role of instability with resistance training. J. Strength Cond. Res. 20, 716-722. doi: 10.1519/00124278-200608000-00039

Behm, D. G., Colado, J. C., and Colado, J. C. (2013). Instability resistance training across the exercise continuum. Sports Health 5, 500-503. doi: $10.1177 / 1941738113477815$

Bottaro, M., Machado, S. N., Nogueira, W., Scales, R., and Veloso, J. (2007). Effect of high versus low-velocity resistance training on muscular fitness and functional performance in older men. Eur. J. Appl. Physiol. 99, 257-264. doi: 10.1007/s00421-006-0343-1

Burd, N. A., West, D. W., Staples, A. W., Atherton, P. J., Baker, J. M., Moore, D. R., et al. (2010). Low-load high volume resistance exercise stimulates muscle protein synthesis more than high-load low volume resistance exercise in young men. PLoS ONE 5:e12033. doi: 10.1371/journal.pone.0012033

Byrne, J. M., Bishop, N. S., Caines, A. M., Crane, K. A., Feaver, A. M., and Pearcey, G. E. (2014). Effect of using a suspension training system on muscle activation during the performance of a front plank exercise. J. Strength Cond. Res. 28, 3049-3055. doi: 10.1519/JSC.0000000000000510

Calatayud, J., Borreani, S., Colado, J. C., Martin, F., Tella, V., and Andersen, L. L. (2015). Bench press and push-up at comparable levels of muscle activity results in similar strength gains. J. Strength Cond. Res. 29, 246-253. doi: 10.1519/JSC.0000000000000589

Chodzko-Zajko, W. J., Proctor, D. N., Fiatarone Singh, M. A., Minson, C. T., Nigg, C. R., Salem, G. J., et al. (2009). American College of Sports Medicine position stand. Exercise and physical activity for older adults. Med. Sci. Sports Exerc. 41, 1510-1530. doi: 10.1249/MSS.0b013e3181a0c95c,

Churchward-Venne, T. A., Tieland, M., Verdijk, L. B., Leenders, M., Dirks, M. L., de Groot, L. C., et al. (2015). There are no nonresponders to resistance-type exercise training in older men and women. J. Am. Med. Dir. Assoc. 16, 400-411. doi: 10.1016/j.jamda.2015.01.071

Cruz-Jentoft, A. J., Baeyens, J. P., Bauer, J. M., Boirie, Y., Cederholm, T., Landi, F., et al. (2010). Sarcopenia: European consensus on definition and diagnosis: report of the European Working Group on Sarcopenia in older people. Age Ageing 39, 412-423. doi: 10.1093/ageing/afq034

\section{FUNDING}

The authors acknowledge the grants provided by São Paulo Research Foundation (FAPESP) (\#2017/053316 to VA) and National Council for Scientific and Technological Development (CNPq) (\#302801/ 2018-9 to CL).

Cugliari, G., and Boccia, G. (2017). Core muscle activation in suspension training exercises. J. Hum. Kinet. 56, 61-71. doi: 10.1515/hukin-2017-0023

Damas, F., Angleri, V., Phillips, S. M., Witard, O. C., Ugrinowitsch, C., Santanielo, N., et al. (2019). Myofibrillar protein synthesis and muscle hypertrophy individualised responses to systematically changing resistance training variables in trained young men. J. Appl. Physiol. 127, 806-815. doi: 10.1152/japplphysiol.00350.2019

de Vreede, P. L., Samson, M. M., van Meeteren, N. L., Duursma, S. A., and Verhaar, H. J. (2005). Functional-task exercise versus resistance strength exercise to improve daily function in older women: a randomized, controlled trial. J. Am. Geriatr. Soc. 53, 2-10. doi: 10.1111/j.1532-5415.2005.53003.x

Fielding, R. A., LeBrasseur, N. K., Cuoco, A., Bean, J., Mizer, K., and Fiatarone Singh, M. A. (2002). High-velocity resistance training increases skeletal muscle peak power in older women. J. Am. Geriatr. Soc. 50, 655-662. doi: 10.1046/j.1532-5415.2002.50159.x

Fragala, M. S., Cadore, E. L., Dorgo, S., Izquierdo, M., Kraemer, W. J., Peterson, M. D., et al. (2019). Resistance training for older adults: position statement from the national strength and conditioning association. J. Strength Cond. Res. 33, 2019-2052. doi: 10.1519/JSC.0000000000003230

Frontera, W. R., Reid, K. F., Phillips, E. M., Krivickas, L. S., Hughes, V. A., Roubenoff, R., et al. (2008). Muscle fiber size and function in elderly humans: a longitudinal study. J. Appl. Physiol. 105, 637-642. doi: 10.1152/japplphysiol.90332.2008

Granacher, U., Gollhofer, A., Hortobágyi, T., Kressig, R. W., and Muehlbauer, T. (2013a). The importance of trunk muscle strength for balance, functional performance, and fall prevention in seniors: a systematic review. Sports Med. 43, 627-641. doi: 10.1007/s40279-013-0041-1

Granacher, U., Lacroix, A., Muehlbauer, T., Roettger, K., and Gollhofer, A. (2013b). Effects of core instability strength training on trunk muscle strength, spinal mobility, dynamic balance and functional mobility in older adults. Gerontology 59, 105-113. doi: 10.1159/000343152

Gringmuth, R. H., and Jackson, C. (2000). Therapeutic exercise for spinal segmental stabilization in low back pain: scientific basis and clinical approach. J. Can. Chiropr. Assoc. 44:125. doi: 10.1179/108331900786166597

Harris, S., Ruffin, E., Brewer, W., and Ortiz, A. (2017). Muscle activation patterns during suspension training exercises. Int. J. Sports Phys. Ther. 12, 42-52.

Jiménez-García, J. D., Martínez-Amat, A., De la Torre-Cruz, M. J., FábregaCuadros, R., Cruz-Díaz, D., Aibar-Almazán, A., et al. (2019). Suspension training HIIT Improves gait speed, strength and quality of life in older adults. Int. J. Sports Med. 40, 116-124. doi: 10.1055/a-0787-1548

Kibele, A., and Behm, D. G. (2009). Seven weeks of instability and traditional resistance training effects on strength, balance and functional performance. J. Strength Cond Res. 23, 2443-2450. doi: 10.1519/JSC.0b013e3181 bf0489

Kikuchi, N., and Nakazato, K. (2017). Low-load bench press and push-up induce similar muscle hypertrophy and strength gain. J. Exerc. Sci. Fitness 15, 37-42. doi: 10.1016/j.jesf.2017.06.003

Liu, C. J., and Latham, N. (2011). Can progressive resistance strength training reduce physical disability in older adults? A meta-analysis study. Disabil. Rehabil. 33, 87-97. doi: 10.3109/09638288.2010.487145

Liu, C. J., and Latham, N. K. (2009). Progressive resistance strength training for improving physical function in older adults. Cochrane Database Syst. Rev. CD002759. doi: 10.1002/14651858.CD002759.pub2

Ma, X., Sun, W., Lu, A., Ma, P., and Jiang, C. (2017). The improvement of suspension training for trunk muscle power in Sanda athletes. J. Exerc. Sci. Fit. 15, 81-88. doi: 10.1016/j.jesf.2017.09.002 
Macaluso, A., and De Vito, G. (2004). Muscle strength, power and adaptations to resistance training in older people. Eur. J. Appl. Physiol. 91, 450-472. doi: 10.1007/s00421-003-0991-3

Marty, E., Liu, Y., Samuel, A., Or, O., and Lane, J. (2017). A review of sarcopenia: enhancing awareness of an increasingly prevalent disease. Bone 105, 276-286. doi: 10.1016/j.bone.2017.09.008

Maté-Muñoz, J. L., Monroy, A. J., Jodra Jiménez, P., and Garnacho-Castaño, M. V. (2014). Effects of instability versus traditional resistance training on strength, power and velocity in untrained men. J. Sports Sci. Med. 13, 460-468.

McGlory, C., van Vliet, S., Stokes, T. and Mittendorfer, B. (2019). The impact of exercise and nutrition on the regulation of skeletal muscle mass. J. Physiol. 597, 1251-1258. doi: 10.1113/JP275443

Mok, N. W., Yeung, E. W., Cho, J. C., Hui, S. C., Liu, K. C., and Pang, C. H. (2015). Core muscle activity during suspension exercises. J. Sci. Med. Sport 18, 189-194. doi: 10.1016/j.jsams.2014.01.002

Morley, J. E., Anker, S. D., and von Haehling, S. (2014). Prevalence, incidence, and clinical impact of sarcopenia: facts, numbers, and epidemiology-update 2014. J. Cachexia Sarcopenia Muscle 5, 253-259. doi: 10.1007/s13539-014-0161-y

Morton, R. W., Oikawa, S. Y., Wavell, C. G., Mazara, N., McGlory, C., Quadrilatero, J., et al. (2016). Neither load nor systemic hormones determine resistance training-mediated hypertrophy or strength gains in resistance-trained young men. J. Appl. Physiol. 121, 129-138. doi: 10.1152/japplphysiol.00154.2016

Nelson, M. E., Rejeski, W. J., Blair, S. N., Duncan, P. W., Judge, J. O., King, A. C., et al. (2007). Physical activity and public health in older adults: recommendation from the American College of Sports Medicine and the American Heart Association. Med. Sci. Sports Exerc. 39, 1435-1445. doi: $10.1249 / \mathrm{mss} .0 \mathrm{~b} 013 \mathrm{e} 3180616 \mathrm{aa} 2$

Nóbrega, S. R., Ugrinowitsch, C., Pintanel, L., Barcelos, C., and Libardi, C. A. (2018). Effect of resistance training to muscle failure vs. volitional interruption at high- and low-intensities on muscle mass and strength. J. Strength Cond. Res. 32, 162-169. doi: 10.1519/JSC.0000000000001787

Orr, R., Raymond, J., and Fiatarone Singh, M. (2008). Efficacy of progressive resistance training on balance performance in older adults: a systematic review of randomized controlled trials. Sports Med. 38, 317-343. doi: 10.2165/00007256-200838040-00004

Petrella, J. K., Miller, L. S., and Cress, M. E. (2004). Leg extensor power, cognition, and functional performance in independent and marginally dependent older adults. Age Ageing 33, 342-348. doi: 10.1093/ageing/afh055

Ramírez-Campillo, R., Castillo, A., de la Fuente, C. I., Campos-Jara, C., Andrade, D. C., Alvarez, C., et al. (2014). High-speed resistance training is more effective than low-speed resistance training to increase functional capacity and muscle performance in older women. Exp. Gerontol. 58, 51-57. doi: 10.1016/j.exger.2014.07.001
Schoenfeld, B. J., Contreras, B., Ogborn, D., Galpin, A., Krieger, J., and Sonmez, G. T. (2016). Effects of varied versus constant loading zones on muscular adaptations in trained men. Int. J. Sports Med. 37, 442-447. doi: 10.1055/s-0035-1569369

Shinkle, J., Nesser, T. W., Demchak, T. J., and McMannus, D. M. (2012). Effect of core strength on the measure of power in the extremities. J. Strength Cond. Res. 26, 373-380. doi: 10.1519/JSC.0b013e31822600e5

Skelton, D. A., Young, A., Greig, C. A., and Malbut, K. E. (1995). Effects of resistance training on strength, power, and selected functional abilities of women aged 75 and older. J. Am. Geriatr. Soc. 43, 1081-1087. doi: 10.1111/j.1532-5415.1995.tb07004.x

Van Abbema, R., De Greef, M., Craje, C., Krijnen, W., Hobbelen, H., and Van Der Schans, C. (2015). What type, or combination of exercise can improve preferred gait speed in older adults? A meta-analysis. BMC Geriatr. 15:72. doi: 10.1186/s12877-015-0061-9

Van Roie, E., Delecluse, C., Coudyzer, W., Boonen, S., and Bautmans, I. (2013). Strength training at high versus low external resistance in older adults: effects on muscle volume, muscle strength, and force-velocity characteristics. Exp. Gerontol. 48, 1351-1361. doi: 10.1016/j.exger.2013. 08.010

Walker, S., Haff, G. G., Häkkinen, K., and Newton, R. U. (2017). Moderateload muscular endurance strength training did not improve peak power or functional capacity in older men and women. Front. Physiol. 8:743. doi: 10.3389/fphys.2017.00743

Walker, S., Peltonen, H., and Hakkinen, K. (2015). Medium-intensity, high-volume "hypertrophic" resistance training did not induce improvements in rapid force production in healthy older men. Age 37:9786. doi: 10.1007/s11357-0159786-9

Zembron-Łacny, A., Dziubek, W., Rogowski, L., Skorupka, E., and Dabrowska, G. (2014). Sarcopenia: monitoring, molecular mechanisms, and physical intervention. Physiol. Res. 63, 683-691.

Conflict of Interest: The authors declare that the research was conducted in the absence of any commercial or financial relationships that could be construed as a potential conflict of interest.

Copyright (C) 2020 Angleri, Soligon, da Silva, Bergamasco and Libardi. This is an open-access article distributed under the terms of the Creative Commons Attribution License (CC BY). The use, distribution or reproduction in other forums is permitted, provided the original author(s) and the copyright owner(s) are credited and that the original publication in this journal is cited, in accordance with accepted academic practice. No use, distribution or reproduction is permitted which does not comply with these terms. 